\title{
ТРАНСФОРМАЦИЯ ВОСПРОИЗВОДСТВЕННЫХ ОТНОШЕНИЙ В СЕЛЬСКОМ ХОЗЯЙСТВЕ В 1988-2000-Е ГГ.: ДЕЙСТВИЕ СПЕЦИФИЧЕСКИХ ЭКОНОМИЧЕСКИХ ПРАВИЛ ИЛИ МЕЖОТРАСЛЕВАЯ ТРАНСПЛАНТАЦИЯ ИНСТИТУТОВ?
}

\author{
(c) 2020 Ермолаев Константин Николаевич \\ доктор экономических наук, профессор кафедры экономической теории \\ Самарский государственный экономический университет, Россия, Самара \\ Email: ermolaevkn@yandex.ru \\ ( 2020 Иванова Ольга Николаевна \\ аспирант \\ Самарский государственный экономический университет, Россия, Самара \\ Email: afonkino_st@mail.ru
}

Особенности сельского хозяйства обуславливает действие специфических отраслевых институтов. Конкретные институты и их взаимосвязи в аграрном секторе пока недостаточно рассматривались исследователями. В научной литературе рассмотрены некоторые аспекты влияния институтов на производство, развитие отдельных сфер воспроизводства. Объектом исследования являются воспроизводственные отношения в сельском хозяйстве в 1988-2000 гг., предметом - действие институтов предшествующих периодов развития, а также специфических и межотраслевых. Исследование позволило сделать вывод о том, что для успешного завершения преобразований необходимо действие специфических отраслевых институтов семейственности и общинности. Важны также межрегиональный и межотраслевой обмен институтами конкуренции и кредитования. При этом нормы институтов должны гибко реагировать на реакцию индивидов на институциональную среду.

Ключевые слова: аграрный сектор, институт, семейственность, общинность, институт планирования, внутристрановой обмен институтами.

Воспроизводство в аграрном секторе можно определить как систему экономических отношений, складывающихся между индивидами в сферах производства, распределения, обмена и потребления сельскохозяйственной продукции. Индивиды в сельском хозяйстве, как и в любой другой отрасли экономики, стремятся к рациональному использованию ресурсов и получению максимальной прибыли [35]. Это сближает производственные отношения, складывающиеся в сельском хозяйстве и в экономике в целом. В связи с этим современные исследователи указывают на возможности внутристранового межотраслевого и межрегионального обмена институтами [3]. Внесение сельского хозяйства в пункт «д» части 1 статьи 72 Конституции РФ - в область совместного ведения федеральной и региональных властей создает правовые рамки для развития институциональной среды аграрного сектора в этом направлении.

Определенные ограничения для межотрас- левой трансплантации возникают благодаря специфике воспроизводственных отношений. Наиболее полно они обобщены Бруцкусом Б.Д.:

- сельское хозяйство, согласно его исследованиям, не позволяет создать искусственную обстановку и планировать объемы производства;

- в отличие от других секторов экономики в сельском хозяйстве предприятия аграрного сектора ограничены в выборе места расположения в местности с наиболее благоприятной экономической средой, налоговым режимом, условиями транспортировки продукции;

- разнородность природной и экономической среды способствует тому, что потребность в техническом оснащении различных территорий различна;

- использование поверхности земли делает сельское хозяйство производством, рассредоточенным на значительной территории, ставит определенные границы его концентрации; 
- растения и животные в известной степени индивидуализированы, поэтому работа в сельском хозяйстве не может быть механизирована в той же степени, как в других отраслях экономики, где приходится иметь дело с мертвым веществом;

- периодичность физиологических процессов приводит к тому, что сельскохозяйственные работы развиваются в определенной последовательности, в связи с этим специализация, разделение труда возможно в сельском хозяйстве в несравненно меньшей мере, чем в промышленности;

- сельскохозяйственные работы прерывисты, имеют сезонный характер и начало производственного цикла сдвигается в зависимости от климатических условий - централизованное руководство неспособно реагировать достаточно оперативно на изменения в производстве [4, 27].

Обозначенные особенности обуславливают зависимость эффективности отрасли от организаторских способностей индивидов, непосредственно занятых на производстве. В институциональной среде важное значение имеет действие неформального института свободы выбора алгоритма действия в процессе производства. Для российских аграрных реалий - надконституционные неформальные институты семейственности и общинности [40].

В научной литературе сложились различные подходы к трансформации воспроизводственных отношений в аграрном секторе. Экономические историки исследуют проявления эффекта предшествующего развития, но мало касаются воспроизводственных отношений в аграрном секторе [25]. Экономисты-теоретики рассматривают влияние институтов на развитие аграрного сектора [2, 38], институциональную среду современного аграрного сектора [32], отдельные сферы воспроизводственных отношений [6, 16, 28, 36]. Конкретные институты, их взаимосвязи и анализ результативности остаются пока за рамками исследования. Такой подход не позволяет ответить на вопросы: какие институты структурировали воспроизводственные отношения в экономике в целом и были наиболее результативными; почему замедлился процесс трансформации воспроизводства в аграрном секторе с 1988 г. по 2000-е гг.? Функционирование каких экономических правил, специфических или межотраслевых станет основой для дальнейшей трансформации воспроизводства в АПК?

Наша работа базируется на схеме взаимодействия институтов и индивидов О.Уильямсона, согласно которой институты, составляющие институциональную среду, представляют собой надконституционные, экономические и политические правила. Индивиды принимают решения, следуют или нарушают правила, формируют институциональные соглашения. Институциональные соглашения - это добровольные договоренности между индивидами и (или) группами, определяющие способы кооперации и конкуренции [39]. Институциональная среда создает такие условия для образования системы частного либо государственного права собственности.

Если институт соответствует целям и задачам индивидов, то последние активно используют правила в процессе деятельности и организуются в их рамках в институциональные соглашения.

Институциональные изменения в период трансформации воспроизводственных отношений в экономике в целом происходили по нескольким направлениям. Закон «О кооперации в СССР», предшествующие ему законодательные акты («О создании кооперативов общественного питания», «О создании кооперативов по бытовому обслуживанию») [12], с одной стороны, создавали условия для формирования частного права собственности. С другой стороны, проявлялся эффект предшествующего развития и продолжали действовать формальные институты планирования, централизованного уравнительного распределения бюджетных средств и сопровождавшие их действие неформальные институты, тормозившие процесс трансформации воспроизводства.

Рассмотрим детально эффект предшествующего развития. Рамки прежней траектории развития проявлялись в действии института планирования экономической деятельности.

Кооператив добровольно принимал на себя исполнение государственных заказов. Объем продукции, произведенный для государства, включался в план кооператива [8]. Договоры, заключаемые между кооперативами, содержали плановые цифры и составляли основу планов [8]. Образовывалась пирамида, в основании которой лежали договоры, содержащие в себе нормы по выполнению государственного плана (РисуHOK 1). 


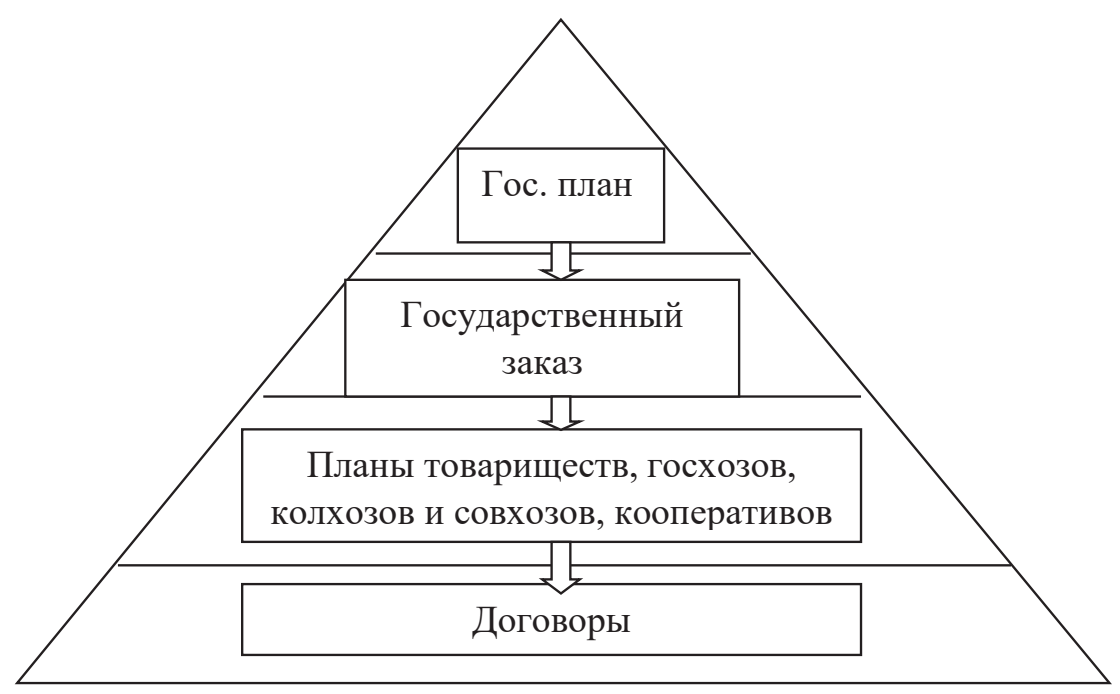

Рисунок 1. Основные составляющие договоров кооперативов согласно закону «0 кооперации в СССР»

Порядок действия института планирования в кооперативах и государственных предприятиях отличался. Каждый кооператив самостоятельно предоставлял в орган управления объемы планируемого производства, реализации и размеры получаемых доходов информацию, которая затем учитывалась в государственных планах [8]. В то же время плановые показатели продолжали «спускаться» в государственные предприятия «сверху» (Рисунок 2).

В рамках действия института планирования экономической деятельности (ст. 18) ведомства продолжали координировать деятельность кооперативов с другими предприятиями и организациями. Механизм координации в виде инсти- тута конкуренции блокировался на формальном уровне [30]. Институт конкуренции можно характеризовать как «нормы, содержащие ситуации конкурентного взаимодействия и правовые механизмы принуждения и побуждения к соблюдению этих норм» [17]. Блокирование на формальном уровне выражалось в отсутствии правовых механизмов конкуренции.

На неформальном уровне конкурентное взаимодействие предполагает состязательность между хозяйствующими субъектами за качество продукции, за урожайность и продуктивность скота и птицы для получения максимальной прибыли. Функционирование института планирования предполагало действие неформальных

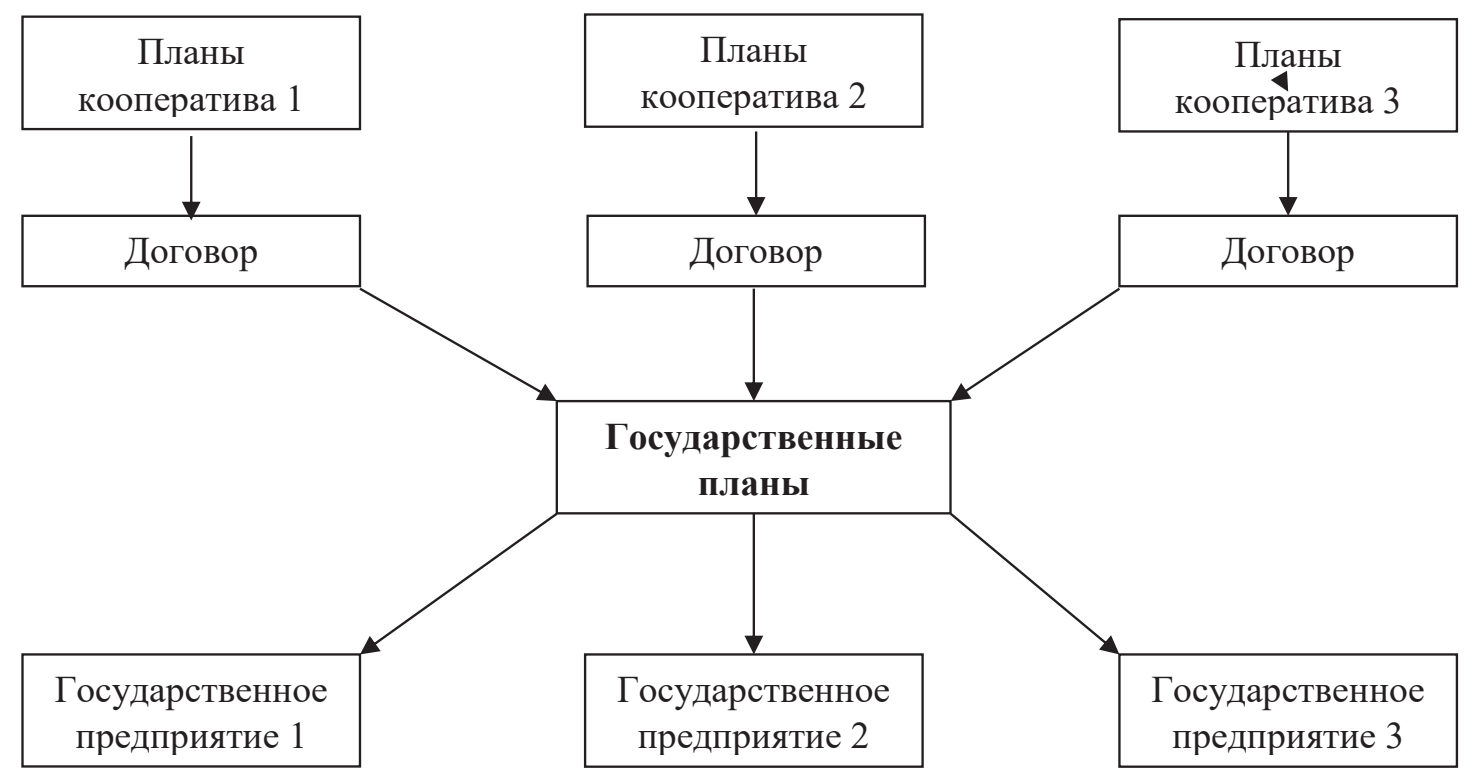

Рисунок 2. Порядок действия института планирования в кооперативах и государственных предприятиях 
институтов, поддерживающих его высокую результативность. Одним из таких деформализованных правил являлся неформальный институт реализации прописанного алгоритма действия и его яркое проявление - социалистическое соревнование. Социалистическое соревнование, как отмечают исследователи, не смогло стать внутренним побудительным мотивом воспроизводственного процесса [5], т.е. самостоятельным устоявшимся высокорезультативным неформальным институтом. Это правило действовало исключительно как «продолжение» института планирования. Согласно закону «О кооперации» «кооперативы активно участвуют в экономическом соревновании с государственными и иными предприятиями и организациями за получение государственных заказов, добиваясь повышения качества продукции (работ, услуг), снижения себестоимости, цен (тарифов)». Институт экономическое соревнование блокировал действие неформального института конкуренции на неформальном уровне (Рисунок 3).

Проявление эффекта предшествующего развития тормозило, но в целом остановить процесс трансформации воспроизводственного процесса в экономике. Индивиды действовали в рамках свободы выбора алгоритма действий в процессе производства, института конкуренции. Например, конкуренция содействовала научнотехническому прогрессу, проявляется в борьбе за более выгодные и экономически оптимальные результаты производства, за лучшее качество оказываемых услуг и продукции [1]:

1. Плескачевский В.С., политический деятель: «24 августа 1988 года мы создали производственный кооператив высотных работ. Мы ремонтировали высотные сооружения без строительных лесов, вися на веревках. Это была су- масшедшая экономия и выгода».

2. Боос Г.В., губернатор Калининградской области в 2005-2010 гг.: «В 1989 году я работал в светотехническом НИИ и вместе с друзьями арендовал там небольшую комнату. Мы занимались разработкой светотехники. Делали освещение офисов и баз отдыха. К этому моменту нас уже было не 5 человек, а 56, и мы получили первый муниципальный заказ - на архитектурное освещение гостиницы «Украина» в Москве. С тех пор предприятие стало организатором всех подобных работ в Москве. Оно и сейчас работает».

3. Надеждин Б.Б., депутат Государственной Думы III созыва: «Когда вышел закон о кооперативах, с товарищами создал кооператив «Интеграл». Мы занимались репетиторством в Москве и области, потом более чем в 100 городах России. Мы не только готовили школьников в вузы, но и выпускали учебную литературу. Мы быстро схватывали пожелания рынка, и прибыль была колоссальная» [24].

Трансформация экономических отношений в сфере производства сопровождались изменением институтов в сфере распределения.

В 1984 г. на декабрьском Пленуме ЦК КПСС перед образованным в 1982 г. отделом экономики при ЦК КПСС была поставлена задача реорганизовать кредитно-финансовую систему. Постепенно были ужесточены требования к кредитованию. В 1987 г. была реализована банковская реформа. Система, состоявшая из Госбанка СССР, Стройбанка СССР, Внешторгбанка СССР и сберегательных касс в систему специализированных на кредитовании отдельных отраслей спецбанков - Промстройбанка, Жилсоцбанка, Агропромбанка, Сбербанка при сохранении Внешэкономбанка и ведущей роли Госбанка СССР. Специализация банков не была достигнута,

\begin{tabular}{|c|c|c|}
\hline & $\begin{array}{c}\text { Институт планирование } \\
\text { экономической деятельности }\end{array}$ & Институт конкуренции \\
\hline Формальный & $\begin{array}{c}\text { Механизм координации } \\
\text { взаимодействия предприятий }\end{array}$ & $\begin{array}{c}\text { Правовой механизм } \\
\text { взаимодействия предприятий }\end{array}$ \\
\hline Неформальный ур-нь & $\begin{array}{c}\text { Соревнование в реализации } \\
\text { прописанного алгоритма } \\
\text { действия, выполнение плана }\end{array}$ & $\begin{array}{c}\text { Состязательность в качестве } \\
\text { продукции, росте урожайности } \\
\text { и продуктивности }\end{array}$ \\
\hline
\end{tabular}

Рисунок 3. Схема блокирования конкуренции института планирование 
их потенциал по развитию различных секторов экономики не был реализован. В условиях углубляющегося кризиса, возрастающего дефицита бюджета, роста доли убыточных предприятий (просроченная задолженность по ссудам Промстройбанка составляла свыше 1 млрд. руб.) уже в конце 1989 г. началось акционирование государственных Жилсоцбанка, Агропромбанка, Промстройбанка. Отраслевая специализация новых коммерческих банков не была определена. В результате все больше банков уходили из производственной сферы в финансово-торговую [13]. 24 августа 1988 г. в городе Чимкент Казахской ССР организовывался первый кооперативный банк - «Союз-банк» [19]. Период с 1988 г. по 1991 г. стал временем быстрого роста банковского сектора [10]. К середине 1991 г. в России существовало около 1 тыс. коммерческих банков [11]. Кредитование на принципах возвратности, срочности, платности становиться институтом с высоким результатом действия. Так, с 2000 по 2010 объем кредитов, предоставленных организациям возрос в 18 раз (с 821 млрд. руб. до 14530 млрд. руб.) [23].

Институт кредитования можно определить как систему формальных и неформальных норм, регламентирующих финансовые взаимоотношения кредитора и заемщика на принципах срочности, возвратности и платности. В рамках института кредитования в обозначенный период в экономике в целом осуществлялось инвестирование в развитие предприятий, стимулирование индивидов. Банковский сектор прекратил финансирование убыточных предприятий. Административное уравнительное распределение было замещено инвестиционными интересами предприятий.

Институты конкуренции и кредитования показали высокий результат действия - в конце 1988 г. было зарегистрировано 77 тыс. кооперативов, в начале 1990 г.- 193, 1 тыс., в которых работало 4,9 млн. чел [14]. В 1990 г. институт частной собственности окончательно сформировался [9].

Институциональная среда в АПК РФ в 19881991 гг. показала низкий результат действия. В аграрном секторе на 1 января 1990 г. было зарегистрировано всего 8,5 тыс. кооперативов, в которых работало 99,7 тыс. чел. [21] Система частного права собственности в этот период не была сформирована.

Институциональная среда сформировала условия для функционирования частного права собственности в аграрном секторе в 1993 г., когда Конституция закрепила право частной собственности на землю. Сельскохозяйственная продукция, сырье и продовольствие являлись теперь собственностью товаропроизводителя и находятся в полном его распоряжении [22].

Эффект предшествующего развития в аграрном секторе ярко проявился в действии института централизованного уравнительного распределения бюджетных средств. Финансирование сельскохозяйственных предприятий осуществлялось по уравнительному принципу компенсации расходов на средства производства весь период реформ до сегодняшнего дня.

В 1992 г. мерой поддержки в условиях диспаритета цен стало финансирование в рамках уравнительного распределения. В 1994 г. начала действовать масштабная по объему выделенных средств программа льготного лизинга сельскохозяйственной техники.

Государственная программа реализовывалась через единственную компанию - сначала через частную компанию с незначительным государственным участием «Агроснаб». В 2001 г. была образована государственная лизинговая компания ОАО «Росагролизинг», фактически монополизировавшая рынок лизинга сельскохозяйственной техники [26]. В 2006 г. принимается закон «О развитие сельского хозяйства». В рамках нацпроекта «сельское хозяйство» реализовывались различные программы развития. Ключевым направлением ОАО «Росагролизинг» с этого момента становиться участие в реализации государственных программ. Сегодня - это исполнение Государственной программы развития сельского хозяйства и регулирования рынков сельскохозяйственной продукции, сырья и продовольствия на 2013-2020 гг. [18]

Институт централизованного целевого уравнительного распределения бюджетных средств в СССР способствовал реализации планирования. Одновременно с плановым заданием на производство сельскохозяйственной продукции каждое сельскохозяйственное предприятие получало плановую цифру разрешенной для него покупки средств производства - техники, оборудования, материалов, удобрений, химикатов. На протяжении 1990-2000-х гг. этот институт также действовал совместно с институтом планирования. Так, согласно Государственной программе развития сельского хозяйства и регулирования 
рынков сельскохозяйственной продукции, сырья и продовольствия на 2008-2012 гг. валовой сбор зерна должен повыситься к 2020 году до 115 млн. тонн против 85,2 млн. тонн в среднем за 2006-2010 годы, или на 34,97 процента, сахарной свеклы - до 41 млн. тонн против 27,1 млн. тонн, или на 51,2 процента [20]. Эти институты блокировали действие институт свободы выбора алгоритма действий, института кредитования, института конкуренции и тормозили трансформацию воспроизводства в АПК.

Индивиды в рамках института планирования вынуждены использовать в деятельности неформальный институт реализации прописанного алгоритма действий. Этот институт блокировал действие института конкуренции на неформальном уровне. Процесс преобразование сферы сбыта замедлился.

Финансирование аграриев по уравнительному принципу блокирует трансформацию и сферы распределения. ОАО «Россельхозбанк», созданный в 2000 г., на 100\% принадлежит государству в лице Федерального агентства по управлению госимуществом [31]. С момента начала реализации национального проекта «Развитие АПК» в 2006 г. является активным участником финансирования реализации государственных программ.

В результате, институт кредитования на основе стимулирования развития крупных инвестиционных проектов, в рамках которых индивиды свободно выбирали бы алгоритм действия в процессе производства, практически не действует в институциональной среде. На 01.01.2011 г. доля ОАО «Россельхозбанк» в общем объеме кредитов, представленных АПК составляет $75 \%$, основная доля государственных средств расходуется на уравнительное финансирование. Например, в 2011 г. в Рязанском филиале выдача кредитов по госпрограмме 20082012 гг. составляла 82,4\% [34].

Результативность программ распределения денежных средств на принципе уравнительности крайне низка:

1. В соответствии с государственной программой развития малых форм хозяйствования на селе в 2006-2007 гг. Россельхозбанком было выдано 300 тыс. кредитов на развитие личных подсобных хозяйств, в т.ч. в 2006 г. -120 тыс. Согласно сельскохозяйственной переписи в 2006 г. зафиксировано 22,8 млн. ЛПХ. Т.е. только $1 \%$ от общего числа ЛПХ действовали в рамках инсти- туциональной среды. В 2015 г. в рамках реализации госпрограмм, включая кредиты предприятиям и организациям АПК, К(Ф)Х, гражданам, ведущим личное подсобное хозяйство $-455,6$ тыс. [37]

2. Объем выданных кредитов сельскому хозяйству не имеет устойчивой тенденции роста. Так, в 2017 г. по сравнению с 2015 г. кредитный портфель сократился на 17 млрд. За этот период на 12,2\% (на 19 млрд.) выросла просроченная задолженность по всем платежам [33].

3. Опросы индивидов, получивших кредит для развития в АПК в АО Россельхозбанк, свидетельствуют о низком качестве услуг. Индивиды отметили плохое качество и узкий целевой характер комплекса предлагаемых кредитных продуктов. Исследователи отмечают - осуществляется кредитование только личных подсобных и крестьянских (фермерских) хозяйств. Нет практики кредитования индивидов, желающих жить селе [7].

Стратегия банка предполагает увеличение рыночной доли в кредитовании АПК [29]. Это поможет ускорить процесс трансформации сферы распределения и воспроизводственных отношений в целом. На сегодняшний день результативность институциональной среды крайне низка. По данным сельскохозяйственных переписей число институциональных соглашений, образованных индивидами, сокращается. Число сельскохозяйственных организаций и К(Ф)Х в 2016 г. по сравнению с 2006 г. сократилось на 40\%, число ЛПХ - на 20\% (с 22,8 млн. до 18,2 млн.) [15].

Для институциональной среды характерна деструктивная результативность. В 2000-е около $40 \%$ зарегистрированных сельхозпроизводителей фактически не вели хозяйственной деятельности [26]. Действуя в рамках уравнительного распределения бюджетных средств, планирования, реализации прописанного алгоритма действия, индивиды на протяжении всех лет реформ активно создавали предприятия-двойники на базе обанкротившихся сельхозтоваропроизводителей. «Новые» сельхозпредприятия получали в бюджетные средства в прежних рамках до следующей процедуры банкротства [26].

Для успешной трансформации воспроизводственного процесса необходимо действие результативных формальных и неформальных норм. Такими институтами должны стать специфические внутриотраслевые неформальные институты семейственности, общинности, сво- 
боды выбора алгоритма действия в процессе производства. Важной составляющей институциональных преобразований в этом направлении может стать межрегиональная трансплантация институтов.

В ходе межотраслевой трансплантации в институциональной среде аграрного сектора должны начать действовать институты кредитования и конкуренции. При этом в особой институциональной среде аграрного сектора отдельных регионов они, несомненно, приобретут свои, отличные от других аналогичных институтов нормы на формальном и неформальном уровнях.

Для того, чтобы внутристрановая трансплантация институтов не привела к возникновению низкорезультативных или деструктивно результативных правил, нормы институтов должны гибко реагировать на реакцию индивидов на институциональную среду.
Таким образом, институциональная трансформация экономики в 1988-1991 гг. создала условия для образования частного права собственности. Действие неформальных институтов свободы выбора алгоритма действия в процессе производства, конкуренции и формального института кредитования позволило «сойти» с траектории предшествующего развития. Институт планирования, централизованного целевого уравнительного распределения бюджетных средств продолжали действовать в аграрном секторе. Это замедляло процесс трансформации воспроизводственных отношений. Для успешного завершения преобразований необходимо введение в действие специфических отраслевых институтов семейственности и общинности, в том числе их межрегиональная трансплантация, а также межотраслевой обмен институтами конкуренции и кредитования.

\section{Библиографический список}

1. Архипов А. М. Роль конкуренции в развитии рыночной экономики // Инновации и инвестиции. 2017 . № 4 (43). С. 56-65.

2. Бабаян И. В. Институциональные условия и факторы развития аграрного сектора экономики: дис. кандидат экономических наук: 08.00.01 - Экономическая теория. Саратов. 2011. 160 с.

3. Байдуллин А. Э. Взаимная трансплантация институтов секторов российской экономики: автореферат дис.... кандидата экономических наук: 08.00.01 / Байдуллин Адель Энверович; [Место защиты: Финансовый ун-т при Правительстве РФ].- Москва, 2018.-26 с.

4. Бруцкус Б.Д. Экономия сельского хозяйства / Книгоиздательство «Кооперативная мысль».- Берлин, 1923. $360 \mathrm{c.}$

5. Горбачева В.Ю. Экономические формы состязательности: рыночная конкуренция и социалистическое соревнование // Вестник Санкт-Петербургского университета. 2008. Сер. 5. Вып. 2. С. 145-149.

6. Гуцелюк, Елена Федоровна. Экономико-институциональный механизм аграрного рынка и его государственное регулирование в переходной экономике: дис. ... канд. экон. наук: 08.00.01, 08.00.05: Ростов н/Д, 2002. 185 c.

7. Дьяченко Н.В., Титова А. В. Совершенствование системы развития кредитных услуг в АПК (на примере Россельхозбанка) // Известия Иркутской государственной экономической академии (Байкальский государственный университет экономики и права). 2011. № 4. С. 4.

8. Закон СССР от 26.05.1988 N 8998-ХІ (ред. от 07.03.1991, с изм. от 15.04.1998) «О кооперации в СССР». Доступ из справ.-правовой системы «КонсультантПлюс». [сайт]. URL: http://www.consultant.ru/document/cons_doc_ LAW_1361/ (дата обращения 14.07.2020).

9. Закон СССР от 6 марта 1990 г. N 1305-I «О собственности в СССР». Доступ из справ.-правовой системы «Гарант». [сайт]. URL: https://base.garant.ru/5171153/ (дата обращения 14.07.2020).

10. Кирсанов Р.Г.История развития банковской системы в России в 1990-х гг.: институциональный аспект // Бюллютень науки и практики. 2016. № 10 (11). С. 181-186.

11. Кирсанов Р. Г. Кооперативный бум. Какими были первые шаги к капитализму? [Электронный ресурс] // Живая история. 26 октября 2017. URL: http://history.ru/statyi/kooperativnyj-bum (дата обращения 11.07.2020).

12. Кирсанов Р.Г. Развитие кооперативного сектора в период перестройки и его роль в стабилизации потребительского рынка в СССР // Вестник Волгоградского государственного университета. Сер. 4, Ист. 2014. № 4(28). С. 30-36.

13. Кирсанов Р.Г. Реформирование банковской системы СССР в годы перестройки // Российская история. 2010. № 2. C. 62-72. 
14. Кирсанов Р.Г. Состояние потребительского рынка в СССР (конец 1970-х - начало 1990-х) // Вестник Бурятского государственного университета. 2014. № 7. С. 36-41.

15. Коренева А. Анализ, прогнозы, мнения - Росстат опубликовал первые итоги Всероссийской сельскохозяйственной переписи // Профессиональная сеть фермеров и людей агробизнеса. AGROBOOK. https://agrobook. ru/blog/user/aleksandra-koreneva/rosstat-opublikoval-pervye-itogi-vserossiyskoy-selskohozyaystvennoy

16. Масло В. В. Стратегия развития сельскохозяйственного производства: автореферат дис. ... кандидата экономических наук: 08.00.05 / Рос. гос. аграр. заоч. ун-т.- Москва, 2005. 20 с.

17. Николаева E.E., Азарова Т.В. К вопросу о конкуренции как институте // Современные наукоемкие технологии. Региональное приложение № 3 (47), 2016. С. 132-140.

18. О компании AO «Росагролизинг» [Электронный ресурс] / Официальный сайт AO «Росагролизинг». URL: https://www.rosagroleasing.ru/company/ (дата обращения 11.07.2020).

19. Первые шаги к рынку. Возвращение частных банков в СССР [Электронный ресурс] // Официальный сайт Российского исторического общества. URL: https://historyrussia.org/tsekh-istorikov/pervye-shagi-k-rynkuvozvrashchenie-chastnykh-bankov-v-sssr.html (дата обращения 14.07.2020).

20. Постановление Правительства РФ от 14 июля 2012 г. N 717 «О Государственной программе развития сельского хозяйства и регулирования рынков сельскохозяйственной продукции, сырья и продовольствия на 2013-2020 годы». [сайт]. URL: https://www.garant.ru/products/ipo/prime/doc/70110644/\#11000 (дата обращения 10.07.2020)

21. Развитие новых форм хозяйственной деятельности [Электронный ресурс] / Проект «Исторические материалы. URL: https://istmat.info/ (дата обращения 10.07.2020).

22. «О закупках сельскохозяйственной продукции, сырья и продовольствия для государственных нужд»: федеральный закон [Текст]: [принят Гос. Думой 26 октября 1994 г.: одобр. Советом Федерации 17 ноября 1994 г.]. // Аграрное законодательство Российской Федерации: Сборник нормативных правовых актов и документов / Сост. М. С. Пашова.- М.: Юристъ, 1999.

23. Российский статистический ежегодник. 2010: Стат.сб./Росстат.-М., 2010-813 с.

24. С какого кооператива вы начинали? Опрос газеты «Коммерсант» [Электронный ресурс] // Официальный сайт газеты «Коммерсант». URL: https:/www.kommersant.ru/doc/722969 (дата обращения 15.07.2020).

25. «Советское наследство». Отражение прошлого в социальных и экономических практиках современной России / под. ред. Л. И. Бородкина, Х. Кесселя, А. К. Соколова.- М.: Российская политическая энциклопедия (РОССПЭН), 2010. 351 с.: ил.-(Социальная история России ХХ века).

26. Серова Е. В. Аграрная реформа в России переходного периода [Электронный ресурс] / История новой Росиии. URL: www.ru-90.ru/node/1321 (дата обращения 10.07.2020).

27. Социалистическое хозяйство. Теоретические мысли по поводу русского опыта.- Париж: Поиски, 1988.$187 \mathrm{c.}$

28. Толстун 3.И., Сабетова Т.В. Методики оценки интенсивности конкуренции, применимые для рынков аграрной продукции // приоритетные векторы развития промышленности и сельского хозяйства. Материалы II Международной научно-практической конференции. 2019. С. 289-292.

29. Федоров М.Н., Васильева В.А. Совершенствование финансовой стратегии банка в современных условиях (на примере АО «Россельхозбанк») // Вестник научных конференций. 2016. № 6-3(10). С. 109-110.

30. Фридрих фон Хайек. Смысл конкуренции // Современная конкуренция. № 3 (15). 2009. С. $18-27$.

31. Хоришко Е.Г. Увеличение вклада Россельхозбанка в реализацию национального проекта России «Развитие агропромышленного комплекса» // Национальные интересы: приоритеты и безопасность. № 8(29) - 2008 . C. $48-52$.

32. Хуртаев К.А. Развитие институциональной среды сельского хозяйства: автореф. ... канд. экон. наук. М., 2010. 28 c.

33. Чекмарева М.В., ШайхутдиноваН.А. Совершенствование системы кредитования в АО «Россельхозбанк» // Вестник современных исследований. 2018. № 12.2 (27). С. 492-494.

34. Черик О.В., Винникова Л.Б. Особенности кредитования сельскохозяйственных товаропроизводителей ОАО «Россельхозбанк» // Наука и бизнес: пути развития. 2012. № 7(13). С. 144-148.

35. Шабанов М.Г. Развитие и государственная поддержка предпринимательства в сельском хозяйстве региона: на примере Республики Дагестан: дис. кандидат экономических наук: 08.00.05 - Экономическая теория. Махачкала. 2005. 149 с.

36. Шик О.В., Серова Е.В., Янбых Р. Г. Исследование системы бюджетной поддержки аграрного сектора в России // Вопросы государственного и муниципального управления. 2020, № 2, С. 145-167. 
37. Шишкина Д. А. Россельхозбанк на рынке кредитных услуг для АПК // Развитие современной науки: теоретические и прикладные аспекты. 2017. № 12. С. 70-72.

38. Юрин С.В.Институциональные факторы развития аграрной экономики: дис. кандидат экономических наук: 08.00.01 - Экономическая теория. Саратов. 2008. 184 с.

39. Williamson, Oliver E. Hierarchies, Markets, andPower in the Economy: An Economic Perspective, Industrial and Corporate Change (1995). No. 4. P. 21-49.

40. Ivanova O.N., Tagirova N. F., Lunin I. A., Trubetskaya O. V. Fundamental Transformation Of The Russian Agricultural Sector And Institutions (1906-1932 Years) // European Proceedings of Social and Behavioural Sciences EpSBS. Pages 808-817. 